\title{
Use of non-pneumatic anti shock garment in hemorrhagic shock
}

\author{
Vidyadhar B. Bangal ${ }^{1 *}$, Satyajit Gavhane ${ }^{1}$, Sonal Raut ${ }^{2}$, Ujwala Thorat ${ }^{3}$
}

\author{
${ }^{1}$ Department of Obstetrics and Gynecology, Rural Medical College, Pravara Institute of Medical Sciences, Loni, \\ Ahmednagar, Maharashtra, India \\ ${ }^{2}$ IMHI, Jiv Daya Foundation, Mumbai, Maharashtra, India \\ ${ }^{3}$ IMHI, Jiv Daya Foundation, Loni, Ahmednagar, Maharashtra, India
}

Received: 10 December 2018

Accepted: 11 January 2019

\author{
*Correspondence: \\ Dr. Vidyadhar B. Bangal, \\ E-mail: vbb217@rediffmail.com
}

Copyright: (C) the author(s), publisher and licensee Medip Academy. This is an open-access article distributed under the terms of the Creative Commons Attribution Non-Commercial License, which permits unrestricted non-commercial use, distribution, and reproduction in any medium, provided the original work is properly cited.

\begin{abstract}
Background: Non-pneumatic anti-shock garment (NASG) is a first-aid device that reverses hypovolemic shock and decreases obstetric haemorrhage. It consists of articulated neoprene segments that close tightly with Velcro, shunting blood from the lower body to the core organs, elevating blood pressure and increasing preload and cardiac output. The use of an NASG can stabilize a patient while awaiting transport, during transport, or during delays in receiving care at referral facilities.

Methods: A prospective observational study of use of non-pneumatic anti shock garment (NASG) in cases with obstetric hemorrhagic shock was carried out at a tertiary referral center. As soon as severe shock was recognized in the hospital, the anti-shock garment was placed. Data on various parameters related to use of NASG was collected and interpreted to draw conclusions.

Results: NASG was used in 25 cases of hemorrhagic shock during one-year period. Post-partum hemorrhage (36\%) was the commonest indication for NASG use, followed by ruptured tubal ectopic pregnancy (28\%). It was observed that $68 \%$ and $32 \%$ of women had shock index of $1-1.5$ and above 1.5 respectively at the time of application of NASG. The shock index rapidly improved to 0.5-0.9 in $92 \%$ and 1-1.5 in 8 percent of cases respectively after the application of NASG. The NASG was mainly used in labour room (40\%) and emergency department (36\%). NASG was applied by nurses and doctors together in $64 \%$ of cases. NASG was kept for a period 24 hours in $92 \%$ cases. The survival rate was $96 \%$ following use of NASG.

Conclusions: NASG is a temporizing alternative measure in hemorrhagic shock management that shows a trend to reduce hemorrhage related deaths and severe morbidities. NASG should be made available at all health facilities that deal with high risk pregnancies and deliveries.
\end{abstract}

Keywords: Emergency obstetric care, Maternal mortality, Non-pneumatic anti shock garment, Obstetric shock, Postpartum hemorrhage

\section{INTRODUCTION}

Haemorrhagic shock is a rare but serious complication, which may occur in many obstetrical situations. Haemorrhage is a leading cause of maternal death in the developing world. ${ }^{1}$ Death and morbidity secondary to haemorrhage are becoming less common due to early recognition and intervention and improved availability of medical resources. Obstetrical haemorrhage is often acute, dramatic, and underestimated. ${ }^{2}$ Postpartum haemorrhage is a significant cause of maternal death. ${ }^{2}$ Haemorrhage occurs when there is excessive external or 
internal blood loss. ${ }^{3}$ A defined volume is difficult to measure in most situations, and the loss evaluated visually is often underestimated. ${ }^{3}$ In low-resource settings, delays in identifying haemorrhage, delays in transport to facilities from a home birth or from primary care centres, and delays in receiving definitive therapies upon arrival at tertiary facilities contribute to high rates of maternal mortality and morbidity secondary to hypovolemic shock. ${ }^{4}$ Results from the use of the Nonpneumatic anti-shock garment (NASG) (Zoex Corporation, Ashland, or) to stabilize women with obstetric haemorrhage have been published in a case series, a pilot study, and two small comparative studies..$^{5-9}$ The non-pneumatic anti-shock garment (NASG) is a firstaid device that can save lives of women experiencing obstetric hemorrhage from any aetiology. ${ }^{10}$ The use of the NASG reportedly addresses the immediate lifethreatening complication by reversing hypovolemic shock among mothers having shock due to PPH and returns blood to the heart, lungs, and brain by applying pressure to the lower body and abdomen. ${ }^{11}$ The use of an NASG can stabilize a patient while awaiting transport, during transport, or during delays in receiving care at referral facilities. ${ }^{12-14}$

\section{METHODS}

A prospective observational study was carried out for a period of one year at tertiary care hospital located in rural area in Maharashtra, India. Approximately 10,000 deliveries take place per year in this hospital. Majority of complicated and high-risk cases are referred to this hospital from nearby towns and villages. The hospital provides blood bank facility 24 hours a day. Common obstetric emergencies causing hypovolemic shock, that are reported from hospital are postpartum hemorrhage (PPH), ectopic gestation, antepartum hemorrhage (APH), post caesarean shock, retained placenta, inversion of uterus, liver disorders, puerperal sepsis, thromboembolism. NASG is applied by the doctor on emergency duty, whenever patient is reported to have hypovolemic shock. Cases coming from outside with anti-shock garment were not included in the study. As soon as severe shock was recognized in the hospital, the antishock garment was placed. Crystalloid solutions were given intravenously over the first hour at a rate of $1500 \mathrm{~mL}$ per estimated liter of blood loss, then at a maintenance rate of $150 \mathrm{~mL} /$ hour. Vital signs were monitored every 15 to 30 minutes, hourly urine output and intermittent oxygen saturation were used to monitor patients during the use of the anti-shock garment. Definitive medical or surgical management of cases was done. When sufficient blood transfusion and fluid infusion had been given to restore the blood pressure and hemoglobin to $>7 \mathrm{~g} / \mathrm{dL}$, the anti-shock garment was removed in segments at 15-minute intervals with documentation of vital signs before removal of each subsequent portion. The non-pneumatic anti shock garment was used either in casualty, in ward, in operation theatre or intensive care unit in different cases. It was applied by either trained nurses or doctors or both depending on the situation. The criteria for use of NASG were predetermined and thus followed in the hospital. The decision regarding application and removal of NASG was taken by specialist doctors. The vital parameters like state of consciousness, blood pressure, pulse, blood loss assessment, laboratory investigations and emergency medical and surgical management was performed by team of doctors available in the hospital. After initial assessment and starting resuscitative measures, cases are shifted either to labour room or operation theatre, depending on the diagnosis. Separate set of NASG is kept in casualty and labour room in order to avoid the delay in procurement from other places in the hospital. Patients of obstetric hemorrhage or shock are shifted to operation theatre and are operated with NASG in situ. Cases developing hypotension during surgery were put on NASG along with fluids management, plasma expanders, blood or components and ionotropic drugs. Critical patients are shifted from operation theatre to postoperative ward or surgical intensive care unit for observation. The segments of NASG are released, one by one, as per recommendations and instructions of the intensivist, depending on the clinical and hemodynamic condition of the patients. Data was collected on various parameters related to use of NASG and interpreted to draw conclusions.

Jiv Daya Foundation (JDF) is an international health agency working since year 2002 with the mission of improving the quality of life of people around the world. As one of the important activities, maternal health improvement programmed is being carried out through its India maternal health initiative (IMHI). Jiv Daya's approach involves building sustainable partnerships and strengthening existing infrastructure for medical institutions in India. JDF provides support to medical institutes having high volume work, with the objectives to impart knowledge on newer techniques and modalities of managing obstetrics emergencies and trauma (MOET) for the benefit of peripheral medical officers from referring district. JDF has provided in kind donation in the form of NASG and other equipment's and medication to more than 35 institutions having high volume work.

\section{RESULTS}

NASG was used as first aid during management of 25 cases of haemorrhagic shock. It was observed that $60 \%$ of women were below 25 years of age, indicating most fertile period in women. The mean age of women was 22.7 years, with minimum age of 17 years and maximum age of 31 years. Sixty six percent of the women were either second or third gravida. It was seen that majority of the women $(84 \%)$ were educated up to higher secondary level and $48 \%$ women had either one or two antenatal visits, indicating lower literacy among women from rural area and early marriages and less awareness about importance of antenatal care. It was observed that $56 \%$ of women with obstetric haemorrhage were in third 
trimester of pregnancy and $32 \%$ were in first trimester of pregnancy. Ruptured ectopic pregnancy with intra peritoneal haemorrhage was the main cause for shock in first trimester of pregnancy. Among all cases of obstetric haemorrhage, $56 \%$ of the women were postnatal cases (Table 1).

Table 1: Patient characteristics.

\begin{tabular}{|l|l|}
\hline Patient characteristics & No. of cases (\%) \\
\hline Age in years & $07(28)$ \\
\hline$<20$ & $08(32)$ \\
\hline $20-25$ & $07(28)$ \\
\hline $26-30$ & $03(12)$ \\
\hline$>30$ & \\
\hline Parity & $04(16)$ \\
\hline Primi & $09(36)$ \\
\hline Second & $08(32)$ \\
\hline Third & $03(12)$ \\
\hline Fourth & $01(04)$ \\
\hline Fifth and $>$ & $04(16)$ \\
\hline Education & $10(40)$ \\
\hline Primary & $07(28)$ \\
\hline Secondary & $03(12)$ \\
\hline Higher secondary & $01(04)$ \\
\hline Graduation & \\
\hline Post-graduation & $12(48)$ \\
\hline Number of antenatal visits & $04(16)$ \\
\hline $1-2$ & $09(36)$ \\
\hline $3-5$ & $08(32)$ \\
\hline$>5$ & $02(08)$ \\
\hline Gestational age (weeks) & $13(52)$ \\
\hline$<12$ & $02(08)$ \\
\hline $13-28$ & $11(44)$ \\
\hline $29-40$ & \\
\hline$>40$ & \\
\hline Delivery status at the time of application of NASG \\
\hline $\begin{array}{l}\text { Undelivered (includes ectopic } \\
\text { gestation and abortions) }\end{array}$ \\
\hline Delivered & \\
\hline & \\
\hline
\end{tabular}

In the present study it was observed that the shock following post-partum haemorrhage was the commonest indication for use of NASG. There were $9(36 \%)$ cases of $\mathrm{PPH}$, who had haemorrhagic shock, of which 7 (28\%) were due to atonic PPH and $2(8 \%)$ were due to traumatic PPH. Next common indication for NASG use was haemorrhagic shock due to intra-peritoneal bleeding following ruptured tubal ectopic pregnancy. All cases of ectopic rupture had come in an emergency, mostly from either private practitioners or from sonologist. There were 3 cases of ante-partum haemorrhage, of which 2 cases had severe variety of accidental haemorrhage and 1 case of placenta praevia. There was 1 case of acute inversion of uterus, who was referred from government hospital. This patient was in severe shock and was in gasping state, so was immediately shifted to intensive care unit for ventilator support. There was a postnatal case of severe viral hepatitis, who had multi-organ failure and shock (Table 2).

Table 2: Indications for application of NASG.

\begin{tabular}{|l|l|}
\hline Indication & $\begin{array}{l}\text { No. of } \\
\text { cases (\%) }\end{array}$ \\
\hline $\begin{array}{l}\text { Post-partum hemorrhage } \\
\begin{array}{l}\text { Ruptured ectopic pregnancy with } \\
\text { hemoperitoneum }\end{array}\end{array}$ & $09(36)$ \\
\hline Antepartum hemorrhage & $07(28)$ \\
\hline Post LSCS shock & $03(12)$ \\
\hline Acute inversion of uterus with shock & $02(08)$ \\
\hline Retained placenta with shock & $01(04)$ \\
\hline $\begin{array}{l}\text { Inevitable abortion with severe bleeding } \\
\text { in shock }\end{array}$ & $01(04)$ \\
\hline Severe hepatitis with multi-organ failure & $01(04)$ \\
\hline
\end{tabular}

The shock index was assessed at the time of admission or at the time of application of NASG in all 25 cases and it was again reassessed at the time of removal of the NASG. It was observed that $68 \%$ and $32 \%$ of women had shock index of 1-1.5 and above 1.5 respectively, at the time of application of NASG. The shock index rapidly improved to $0.5-0.9$ in $92 \%$ and in between 1-1.5 in 8 percent of cases respectively, after application of NASG and other resuscitative measures that include intravenous fluids, blood and components and correction of acidosis and use of ionotropic drugs in majority of cases (Table 3).

Table 3: Shock index at the time of NASG application and removal.

\begin{tabular}{|l|l|l|}
\hline $\begin{array}{l}\text { Shock } \\
\text { index }\end{array}$ & $\begin{array}{l}\text { At the time of } \\
\text { application of } \\
\text { NASG no. }(\%)\end{array}$ & $\begin{array}{l}\text { At the time of } \\
\text { removal of NASG } \\
\text { no. }(\%)\end{array}$ \\
\hline $0.5-0.9$ & $00(00)$ & $23(92)$ \\
\hline $1-1.5$ & $17(68)$ & $02(08)$ \\
\hline$>1.5$ & $08(32)$ & $00(00)$ \\
\hline
\end{tabular}

Restoration of blood pressure and improvement of mental status occurred within 5 minutes in seven cases who were pulseless and three who were unconscious or confused. All patients had improvement of mean arterial pressure to greater than $80 \mathrm{~mm} \mathrm{Hg}$ within 5 minutes. Patients were comfortable during use of the anti-shock garment. In the present study, the NASG was mainly used in labour room $(40 \%)$ in cases of postpartum haemorrhage and sometimes in cases of accidental haemorrhage. Another common place was casualty department or emergency department (36\%), which is an entry point for hospital. At times NASG was used in either operation theatre or its recovery room $(12 \%)$ or in ward or intensive care unit (12\%). In majority of cases, NASG was applied by nurses and doctors (64\%) together at all locations as mentioned above. In few cases, NASG was applied by only doctors $(24 \%)$ or by only nurses $(12 \%)$. The NASG was used for $12-24$ hours in $52 \%$ cases and for 6-12 hours in $32 \%$ 
cases. It was used for less than 6 hours and more than 24 hours in $8 \%$ cases each. In the present study, majority of cases $(96 \%)$ survived following use of NASG (Table 4).

Table 4: NASG utilization and outcome details.

\begin{tabular}{|l|l|}
\hline NASG utilization and outcome & $\begin{array}{l}\text { No. of } \\
\text { cases (\%) }\end{array}$ \\
\hline Place of application of NASG & $10(40)$ \\
\hline Labour room & $09(36)$ \\
\hline Casualty/Emergency/Triage room & $03(12)$ \\
\hline $\begin{array}{l}\text { Operation theatre/Recovery room } \\
\text { Intensive care unit/ward }\end{array}$ & $03(12)$ \\
\hline Person who applied NASG & $06(24)$ \\
\hline Labour room & $03(12)$ \\
\hline Casualty/Emergency/Triage room & $16(64)$ \\
\hline Operation theatre/Recovery room & \\
\hline Duration of application of NASG & $02(08)$ \\
\hline <6 hours & $08(32)$ \\
\hline $\begin{array}{l}\text { 6-12 hours } \\
\text { 13-24 hours }\end{array}$ & $13(52)$ \\
\hline$>24$ hours & $02(08$ \\
\hline $\begin{array}{l}\text { Patient survival status following application of } \\
\text { NASG }\end{array}$ & $24(96)$ \\
\hline Survived & $01(04)$ \\
\hline Died & \\
\hline
\end{tabular}

\section{DISCUSSION}

Obstetric hemorrhage is the leading cause of maternal mortality in India. In addition to non-recognition of highrisk pregnancies and timely referrals, the delays at all levels contribute in causation of maternal deaths. Three types of delays have been identified, which contribute to death in PPH. Delay in decision making by patient and relatives regarding seeking institutional care and delay in transport of PPH cases to appropriate health care facility are main causes of delays. At times there is delay in providing care at the health facility level either due to lack of doctors or the drugs, blood products, oxytocic's and equipment's at the health care facility. Time lapse between occurrence of PPH and reaching to tertiary care facilities determines the outcome. Unfortunately, there is very narrow margin of safety as regards to time. Treatment received in first two hours, following PPH determines the survival. Institutional deliveries and facility preparedness to tackle this complication help in saving life of young women. In order to avoid type three delay, facility preparedness to deal with postpartum hemorrhage is very crucial. Non- pneumatic Anti-Shock Garment (NASG) is a unique, life-saving first-aid device made of neoprene and Velcro, which is used on women with obstetric hemorrhage. It can be applied by anyone, even those without medical training. The NASG has a unique role in hemorrhage and shock management because it is meant to be used with, not instead of, other technologies. Currently, it is the only tool that aids in stabilizing pulse and blood pressure after a woman has gone into shock from obstetric hemorrhage. NASG can reverse shock and can be used at the same time with other hemorrhage and shock treatments, such as: uterine massage, uterotonics, blood transfusions, Vaginal procedures and surgery, uterine balloon tamponade. A pregnant woman suffering from severe hemorrhage can die within two hours, unless she receives immediate and prompt medical care; therefore, when delay in managing hemorrhage occurs, first aid is needed to resuscitate and stabilize women with hypovolemic shock until definitive treatment is obtained. ${ }^{15-17}$ NASG is mainly useful to stabilize a patient while evaluating, transporting, and preparing for definitive surgical treatment.A woman can safely and comfortably wear the NASG for up to 48 hours. The NASG remains on the woman during treatments and until she has been hemo-dynamically stable for 2 hours. NASG has 6 segments. Segment 1, 2, and 3 (in pairs) are placed around the patient's legs, Segments 4, 5and 6 are placed around pelvis and abdomen, A ball in segment 5 and segment 6 is placed over the woman's umbilicus, adding more pressure. Segment 6 is closed over segment. ${ }^{5}$ Indications for the use of NASG are to manage any condition, where there is severe bleeding below the diaphragm, all forms of obstetric hemorrhage (in excess of $750 \mathrm{ml}$ ) like in ectopic pregnancy, abruption, acute or chronic, placenta praevia, ruptured uterus, hydatidiform mole,spontaneous abortion. After delivery NASG is used in uterine atony, retained products of conception, obstetrical trauma. The contraindications for the use of NASG are A viable fetus (unless there is no other way to save the mother's life and both mother and fetus will die), bleeding above diaphragm, open thoracic wounds, patients with severe congestive heart failure or pre-existing mitral stenosis. In trauma victims with injury to the chest or head, redistribution of blood to the injured area with NASG placement raises the possibility of associated increased hemorrhage.

Due to non-availability of NASG in public health system, majority of doctors and nurses have not even seen or heard about NASG. Very few gynecologists have heard about it but had not seen or used it in clinical practice. In a study published from UCH, Ibadan, awareness about the existence of anti-shock garment was high among midwives as $96 \%$ of the respondents said they have heard about it through seminars, conferences and other means. Many of them could describe NASG application, removal and its general function in the prevention of post-partum hemorrhage. Majority of them could correctly explain various advantage of NASG as well as some maternal and fetal conditions that are contraindicated in the use of NASG. It shows that many of them have been exposed to the use of anti-shock garment through workshops, conferences and seminars. However, this seems to be the limit of their knowledge; many of them have never applied it on bleeding woman. Their knowledge seems to be only theoretical as only $35 \%$ of them have had opportunities to apply NASG; the rest $65 \%$ had never applied it on clients. Because the respondents have never had opportunity to apply NASG on bleeding woman, 
their theoretical knowledge is of little use. ${ }^{7,10,18}$ The researchers have compared the morbidity and mortality outcomes using the NASG to outcomes with standard treatment of shock/hemorrhage in women with a variety of obstetric hemorrhage $(\mathrm{OH})$ aetiologias, and the NASG was found to be effective in decreasing blood os by over $50 \%{ }^{7,10,18,19}$ A systematic review including 5 studies and 1247 women with shock found a decreased mortality of 48\% (Relative Risk (RR) 0.52 (95\% Confidence interval (CI) 0.36 to 0.77 ) at referral, tertiary-level facilities. ${ }^{12} \mathrm{~A}$ cluster randomized clinical Trial (CRCT) was conducted in Zimbabwe and Zambia to determine if early application of the NASG at the primary health facility level improved outcomes compared to later application at the referral facilities. ${ }^{19}$ The reduction in mortality was clinically significant at $55 \%$, but there was an inadequate sample of women in hypovolemic shock (actual sample size, $n=880$ vs. the predicted $n=2400$ ) necessary to have adequate power to determine statistical significance. ${ }^{20}$ The NASG is currently recommended by the International Federation of Gynecologists and Obstetricians (FIGO)] and the World Health Organization (WHO) and can be found in PPH guidelines and manuals, such as WHO (Managing Complications $2^{\text {nd }}$ Edition) Global Library of Women's Medicine (GLOWM) PPH Recommendations and JHPIEGO's helping mothers survive bleeding after birth as well as in JHPIEGO's 2018, 5-year report "Survive and Thrive". ${ }^{21-26}$ A healthcare technology assessment performed for WHO resulted in a positive recommendation for including the NASG in emergency maternal and obstetric care (EMOC) management. ${ }^{27}$ Despite these global recommendations and endorsements and despite pilot implementation and scale up projects conducted in India Nigeria, Ethiopia, Niger, Timor Leste and Colombia, there have been fewer publications on how the NASG is accepted and used by clinicians and health systems. ${ }^{28-35}$ The reports on NASG use in Purina and Gaya district from Bihar revealed that the interviews and discussion with stakeholders reflected that even after training and appropriate introduction of the practice of using the NASG, the initiative did not translate into making a difference in ameliorating the situation of $\mathrm{PPH}$ management in the health facilities over a period of the following 6 months. The NASG were procured by national health mission and supplied in ambulances to the facilities. In Gaya district, NASG was supplied in 24 facilities, whereas in Purina, it was available only in few facilities. The ambulance technicians at the respective facilities were in-charge of the NASGs. In both the districts, health personnel were receptive towards the idea of having NASGs at their facilities for use in PPH management.

However, it was reported that though the NASG were readily available in many facilities and staff members were trained in its use; NASG were not being utilized. One of the interviewees mentioned that this was probably because: "Enough training was not provided to them, and they had no idea about how to use the NASG to prevent
PPH cases. "While interacting with the various healthcare providers, it was realized that they lacked skills to identify the cases of PPH and use the NASG garment appropriately. ${ }^{36}$

In low-resource settings nurses have few resources with which to stabilize women with severe obstetric hemorrhage. With training nurses and nurse-midwives can stabilize hemorrhaging women with the NASG, a low-technology first-aid device that shows promise for reducing blood loss, rates of hysterectomy, and mortality. ${ }^{37}$

In the present study, it was observed that all nurses and resident doctors working in labour room, casualty department, operation theatre and intensive care unit were trained in application of NASG. Initially, there were few mistakes in application of some of the segments, but later on every member of the emergency team learnt the correct technique.

\section{CONCLUSION}

Obstetric haemorrhage remains one of the leading causes of maternal mortality, particularly in rural areas. The nonpneumatic anti-shock garment has been demonstrated to reduce mortality as it buys time for women in shock to be transported to or to overcome delays at referral facilities. There is need for training of maternal health care providers in newer modality like NASG a, which has potential to save lives in obstetric haemorrhage cases. government should make NASG available in all health care facilities, for use in an emergency, when it is needed.

As survival of the patient is the utmost goal of any health facility, there should give more freedom to midwives/nurses on provision of life saving procedures as they are key persons in maternal health. One of such area is the application of NASG on bleeding woman. This should not be limited to resident doctors and consultant Obstetricians and Gynaecologists alone. With the proper implementation strategies, NASG utilization can be improved and that would result into decreased mortality among mothers at risk of death from obstetric hemorrhage.

\section{Funding: No funding sources Conflict of interest: None declared Ethical approval: Not required}

\section{REFERENCES}

1. Smith HO. Shock in the gynecologic patient. In: Rock JA, Thomson JD, eds. Te Linde's operative gynecology. 8th ed. Lippincott-Raven; 1997:245261.

2. SOGC Clinical Practice Guidelines. Prevention and management of postpartum hemorrhage. J Soc Obstet Gynaecol Can. 2000;22(4):271-81. 
3. Barber A, Shires GT. Shock. In: Schwartz SI, eds. Principles of surgery. $7^{\text {th }}$ ed. McGraw-Hill. 1999:101-122.

4. McCarthy J, Maine D. A framework for analyzing the determinants of maternal mortality. Studies Family Planning. 1992;23(1):23-3.

5. Brees C, Hensleigh PA, Miller S, Pelligra R. A noninflatable anti-shock garment for obstetric hemorrhage. Int J Gynaecol Obstet. 2004;87:119-4.

6. Hensleigh PA. Anti-shock garment provides resuscitation and haemostasis for obstetric haemorrhage. BJOG: An Int J Obstet Gynaecol. 2002;109(12):1377-84.

7. Miller S, Fathalla MM, Youssif MM, Turan J, Camlin C, Al-Hussaini TK, et al. A comparative study of the non-pneumatic anti-shock garment for the treatment of obstetric hemorrhage in Egypt. Int $\mathbf{J}$ Gynaecol Obstet. 2010;109:20-4.

8. Miller S, Hamza S, Bray E, Gipson R, Nada K, Fathalla MF, Mourad M. First Aid for Obstetrical Haemorrhage: The Pilot Study of the Non-pneumatic Anti-Shock Garment (NASG) in Egypt. BJOG. 2006;113:424-9.

9. Miller S, Ojengbede O, Turan JM, Morhason-Bello IO, Martin HB, Nsima D. A comparative study of the non-pneumatic anti-shock garment for the treatment of obstetric hemorrhage in Nigeria. Int $\mathbf{J}$ Gynaecol Obstet. 2009;107:121-5.

10. Turan J, Ojengbede O, Fathalla M, Mourad-Youssif M, Morhason-Bello IO, Nsima D, et al. Positive effects of the non-pneumatic anti-shock garment on delays in accessing care for postpartum and postabortion hemorrhage in Egypt and Nigeria. J Womens Health (Larchmt) 2011;20:91-8.

11. Non-pneumatic Anti-shock Garment-Compendium of New and Emerging Technologies that Address Global Health Concerns. Geneva: World Health Organization; 2011. Available at: http://www.who.int/medical_devices/innovation/new _emerging_tech_30.pdf. [Last cited on 2016 May 26].

12. Pileggi-Castro C, Nogueira-Pileggi V, Tunçalp Ö, Oladapo OT, Vogel JP, Souza JP. Non-pneumatic anti-shock garment for improving maternal survival following severe postpartum haemorrhage: a systematic review. Reprod Health. 2015;12(1):28.

13. Maknikar S, Nanda R, Miller S. NASG reduces mortality in Indian women with PPH. Int J Gynecol Obstet. 2012;119:S413.

14. Magwali TL, Butrick E, Mambo V, El Ayadi A, Lippman S, Bergel E, et al. O421 non-pneumatic anti-shock garment (nasg) for obstetric hemorrhage: harare, zimbabwe. Int $\mathbf{J}$ Gynecol Obstet. 2012;119(S3).

15. Balachandram V. Maternal Mortaltiy in Kaduna. Nigeria Med J.1995;5:366-70.

16. Bais JM, Eskes M, Pel M, Bonsel GJ, Bleker OP. Postpartum haemorrhage in nulliparous women: incidence and risk factors in low and high-risk women: a Dutch population-based cohort study on standard $(\geq 500 \mathrm{ml})$ and severe $(\geq 1000 \mathrm{ml})$ postpartum haemorrhage. Europ J Obstet Gynecol Reprod Biol. 2004;115(2):166-72.

17. Magann EF, Evans S, Hutchinson M, Collins R, Lanneau G, Morrison JC. Postpartum hemorrhage after cesarean delivery: an analysis of risk factors. South Med J. 2005;98(7):681-6.

18. Miller S, Fathalla MM, Ojengbede OA, Camlin C, Mourad-Youssif M, Morhason-Bello IO, et al. Obstetric hemorrhage and shock management: using the low technology Non-Pneumatic Anti-Shock Garment in Nigerian and Egyptian tertiary care facilities. BMC Pregnancy Childbirth 2010;10(1):64.

19. Miller S, Bergel EF, El Ayadi AM, Gibbons L, Butrick EA, Magwali T, et al. Non-Pneumatic AntiShock Garment (NASG), a First-Aid Device to Decrease Maternal Mortality from Obstetric Hemorrhage: A Cluster Randomized Trial. AbdelAleem H, editor. PLoS One 2013;8(10):e76477.

20. El Ayadi AM, Butrick E, Geissler J, Miller S. Combined analysis of the non-pneumatic anti-shock garment on mortality from hypovolemic shock secondary to obstetric hemorrhage. BMC Pregnancy Childbirth.2013;13:208.

21. André L. Prevention and treatment of postpartum hemorrhage in low-resource settings. Int $\mathbf{J}$ Gynecol Obstet. 2012;117(2):108-18.

22. World Health Organization. WHO recommendations for the prevention and treatment of postpartum haemorrhage. Geneva: World Health Organization; 2012. Available at: http://www.who.int/reproductivehealth/publications/ maternal_perinatal_health/9789241548502/en/.

23. World Health Organization, UNICEF, United Nations Population Fund (UNFPA) Managing complications in pregnancy and childbirth: a guide for midwives and doctors. 2. Geneva: World Health Organization; 2017.

24. Karoshi M, Keith L, Arulkumaran S, Lalonde A. Postpartum hemorrhage: Guidelines for Immediate Action, Wall Chart. Global Library of Women's Medicine. 2012.

25. Nelissen E, Ersdal H, Mduma E, Evjen-Olsen B, Broerse J, van Roosmalen J, et al. Helping Mothers Survive Bleeding After Birth: retention of knowledge, skills, and confidence nine months after obstetric simulation-based training. BMC Pregnancy Childbirth. 2015;15(1):190.

26. Survive and Thrive. Guiding the way forward: Survive and Thrive 5-year Report (2012-2017). 2018. Available at: https://surviveandthrive.org/about/Documents/Surviv e\%20\%20Trive\%205\%20year\%20report\%20FINAL. pdf.

27. Chhaya VA, Sharma JK, Ameel M, Sundararaman T. Healthcare Technology Assessment for NonPneumatic Anti Shock Garment for Obstetric Shock Prevention. Available at: [http://www.who.int/medical_devices/global_forum/ E02.pdf] 
28. Satia J, Misra M, Arora R, Neogi S. Innovations in maternal health: Case studies from India. SAGE Publicat India. 2013;30.

29. Mankikar S, Nanda R, Miller S. NASG reduces mortality in Indian women with PPH. Int J Gynecol Obstet. 2012;119(S3):S413.

30. Sloan NL, Storey A, Fasawe O, Yakubu J, McCrystal K, Wiwa O, et al. Advancing Survival in Nigeria: A Pre-post Evaluation of an Integrated Maternal and Neonatal Health Program. Maternal Child Health J. 2018;22(7):986-97.

31. Demeke Z. Non-Pneumatic Anti-Shock Garment pilot in Ethiopia to reduce maternal mortality secondary to obstetric hemorrhage. CHAI Ethiopia. Presented at the Global Maternal Health Conference 2013.

32. Gebrehiwot Y. Use of the Non-Pneumatic Antishock Garment (NASG) to Reduce Maternal Mortality in Ethiopia. Ethiopia: Tewodros Emiru; 2013.

33. Zeidou A. Lutte contre la mortalite maternal: Experience du Niger. Lome, Togo: Presentation at Togo Ministry of Health Postpartum Hemorrhage Technical Meeting; 2017.

34. John Snow Inc. Timor Leste Health Improvement Project Final Report. 2015. Available at:
https://www.jsi.com/JSIInternet/Inc/Common/_down load_pub.cfm?id=18016\&lid=3.

35. Escobar MF, Füchtner CE, Carvajal JA, Nieto AJ, Messa A, Escobar SS, et al. Experience in the use of non-pneumatic anti-shock garment (NASG) in the management of postpartum haemorrhage with hypovolemic shock in the Fundación Valle Del Lili, Cali, Colombia. Reprod Health 2017;14(1):58. Available http://www.ncbi.nlm.nih.gov/pubmed/28499381.

36. Sharma J, Negandhi P, Das AM, Sethy G, Neogi SB. Using nonpneumatic anti-shock garment for postpartum hemorrhage management and referral at the public health facilities: A pilot study in two districts of Bihar. Indian $\mathbf{J}$ Public Health. 2016;60(4):316-22.

37. Kausar F, Morris JL, Fathalla M. Nurses in low resource settings save mothers' lives with nonpneumatic anti-shock garment. MCN Am J Matern Child Nurs. 2012;37(5):308-16.

Cite this article as: Bangal VB, Gavhane $\mathrm{S}$, Raut $\mathrm{S}$, Thorat U. Use of non-pneumatic anti shock garment in hemorrhagic shock. Int J Reprod Contracept Obstet Gynecol 2019;8:621-7. 